\title{
Developing a Conceptual Model for the Intention to Adopt CC-Saas
}

\author{
Hiba Jasim Hadi, Nafishah Othman, Wan Rozaini Sheik Osman
}

\begin{abstract}
Cloud Computing (CC) is an evolving information technology paradigm providing on-demand IT resources on a pay-as-you-go basis. A cloud computing service model called Software as a Service (SaaS) emerged to offers IT services, effectively utilise computing and power consumption while achieving performance, decreasing cost, and increasing revenue. However, the adoption rates of CC-SaaS among the organisations are inadequate, and its diffusion is not fully explored due to issues related to data security, privacy concerns and trust which affects the adoption of CC-SaaS. There is a lack of empirical studies investigating factors affecting the adoption of CC-SaaS from the organisational perspectives specifically in Iraq. Therefore, the primary aim of this study is to identify the most influencing factors for the intention to adopt CC-SaaS in Iraqi organisations. In order to meet the primary aim, such factors are reviewed and selected from the literature on a high frequency of occurrence and developed the proposed model. The result of the factors is validated by expert and the values of assessment are statistically analysed using SPSS for t-test analysis. The proposed model can give a guide for the decision makers to plan the successful adoption of CC-SaaS in the organisation.
\end{abstract}

Keywords : Cloud computing, DOI, HOT, Intention to adopt, software as a services.

\section{INTRODUCTION}

The Cloud Computing (CC) enables evolutionary online environment that enhanced the ability to handle and expand the bulk of work without any effect on the execution for the Information System (IS) framework [1]. Furthermore, CC is a new-generation Information Communication Technology (ICT) technology that continues to gain popularity due to its pay-as-you-go service model [2]. Thus, CC has the ability to reduces the amount of time, cost and resources required from the ICT's dependencies [3]. This is achieved through enabling the ICT providers to virtualised their computational resources and concurrently provides them via a service orchestration process [4]. Different types of models and theories reviewed from the literature indicate that researchers combine more than one theoretical viewpoint in order to gain more insight about the adoption of new IT innovative technologies. This highlights that getting a better understanding of organisational decisions regarding the

Revised Manuscript Received on February 05, 2020.

* Correspondence Author

Hiba Jasim Hadi*, IASDO Research Laboratory, School of Computing, Universiti Utara Malaysia, Sintok 06010 Malaysia.

Nafishah Othman, IASDO Research Laboratory, School of Computing, Universiti Utara Malaysia, Sintok 06010 Malaysia.

Wan Rozaini Sheik Osman, IASDO Research Laboratory, School of Computing, Universiti Utara Malaysia, Sintok 06010 Malaysia.

(C) The Authors. Published by Blue Eyes Intelligence Engineering and Sciences Publication (BEIESP). This is an open access article under the CC BY-NC-ND license (http://creativecommons.org/licenses/by-nc-nd/4.0/) intention to adopt of any new technological innovation, requires a comprehensive context of a study and the variables to be used should be aligned to the characteristics of the innovation to be adopted [5]. In this paper, the proposed model is presented, which was formulated based on the findings of the previous studies. It was proposed for the examination of the influencing determinant that affects the intention to adopt CC-SaaS. It also begins with the discussion on the theoretical background that initiates the process for the development of the model which support the need to propose a strategic model to assist organisations that have the intention to adopt CC-SaaS. Some well-constructed frameworks based on theory were selected to support the proposed model; these are the TOE Framework, the DOI, and the HOT-fit Framework. Furthermore, this study is expanded for the confirmation of the selected factors by experienced academic and industrial experts. Their validated or confirmation values are statistically analysed using SPSS for t-test analysis. In the future, a model with its influential hypothesis will be formulated for the empirical investigation of these selected factors. Besides, this paper is systematized in five (5) parts or sections, after the introductory Section two (2) presented the related works for theories and model of IT adoption, Section three (3) is the proposed conceptual model and holistic viewpoint, followed by hypothesis development in Section four (4) and the conclusion section.

\section{RELATED WORK}

Different types of models and theories reviewed from the literature indicate that researchers combine more than one theoretical viewpoint in order to gain more insight about the adoption of new IT innovative technologies. This highlights that getting a better understanding of organisational decisions regarding the intention to adopt of any new technological innovation, requires a comprehensive context of a study and the variables to be used should be aligned to the characteristics of the innovation to be adopted [5]. Literature has documented the extensive applications of DOI and TOE framework with consistent empirical support. In the number of instances, there have been overlapping between the TOE and the innovation characteristics reported by Rogers [6]. Thus, combining TOE variables strengthen the DOI theory has been accepted as a valuable idea [5]. The internal and external organisational characteristics of DOI have similar measurements like those of TOE's organisation context [7]. Despite the similarities, there are some key differences between the TOE and DOI. For instance, the role of individual characteristics is not addressed in the TOE framework (e.g. top management support) into its perspectives. 
Contrarily, the inclusion of top management support was suggested under DOI as part of the organisation context. Moreover, TOE framework offers a well-comprehensive perspective for IT understanding in terms of technology, organisation, and environmental contexts, DOI does not give any consideration with regards to the impact of the environmental setting, in essence, the shortcomings of DOI addressed by are the TOE framework in this regards [5].

One of the advantages of TOE framework is its ability to enable researchers to get a broader picture of the innovation process, and this happens due to its integration ability of different factors that affect the adoption into their respective context including technology, organisation, and environment [8] In the existing literature, a considerable empirical supported has been gained by the TOE framework, used in many studies relating to different types of technology adoption [9]. Despite its broader application, the TOE framework has alone neglected the relevance of inter-organisational relationships relating to human factors and also does not consider the importance of combining factors that may address the issue of inconclusive findings [8]. Moreover, many studies that applied the framework paid much emphasis on various technological factors [10] and organisational factors [11], but neglect environmental and human factors in their investigations [11].

Moreover, Mohammed et al., [12] emphasised the consideration of human aspects in the adoption of CC and the relevance of the human factor in the adoption of IT innovation [13]. Also, Yusof [14] stated that human and organisational factors are as important as technical factors with regards to system effectiveness. Especially the adoption of CC-SaaS model in which different IT skills are required at the organisational level of the user. The finding from qualitative research in [15] showed that organisations that adopt these types of IT service models need to significantly enhance their IT skills to match their needs. Specifically, the research revealed that knowledge, skill and experience of the IT personnel need to be enriched in relation to the SaaS technologies, its capabilities as well as its interconnection and integration with existing IT infrastructures in the organisational premises [15]. Therefore, based on these reasons, there is need to provide new procedures for the management of SaaS that can be utilised by humans within the organisation.

Similarly, the HOT-fit model incorporates human with organisational and technological dimensions due to the claim that the human factor has a positive impact on technology adoption [16]. Besides, several studies within the IT adoption literature documented that most of the problems being experienced in innovation adoption were attributed to unfitness between technological, organisational and human contexts. Thus, this study found that HOT-fit can contribute to filling this gap through an empirical investigation from the perspectives of human aspect, in relation to the technology within an environment and related to the organisation. This will enable proper interpretation of various organisational, technological, environmental and human factors relating to the intention to adopt CC-SaaS model.

\section{PROPOSED CC-SAAS INTENTION TO ADOPT MODEL}

The proposed conceptual model is developed through the integration of TOE, DOI and HOT-Fit that comprises eighteen numbers of independent variables, which are used to determine the dependent variable, i.e. intention to adopt CC-SaaS (IASaaS). The eighteen independent variables that are found from the literature are grouped into Technological Dimension (Relative Advantage, Compatibility, Complexity, Security and Privacy), Organisational Dimension (Top Management Support, Technology Readiness, and Organisational Readiness), Environmental Dimension (Government Regulation, Competitive Pressure, External Support and Compliance with Regulation) and Human Dimension (IT Knowledge and IT Personnel Innovativeness). Moreover, the Trust Dimension (Ability, Integrity and Benevolence) is proposed as a mediator in the relationship between the independent variables from two dimensions; Technology and Organisation, and the dependent variable - IASaaS as suggested by Wahsh et al., [17] and Yikai et al., [11]. Similarly, the IT Experience is proposed as a moderator in the relationship between Human factors and IASaaS. Figure 1 illustrates the relationship of the above-stated dimensions and their moderating as well as the mediating factor, which generally represents the proposed conceptual model of this study.

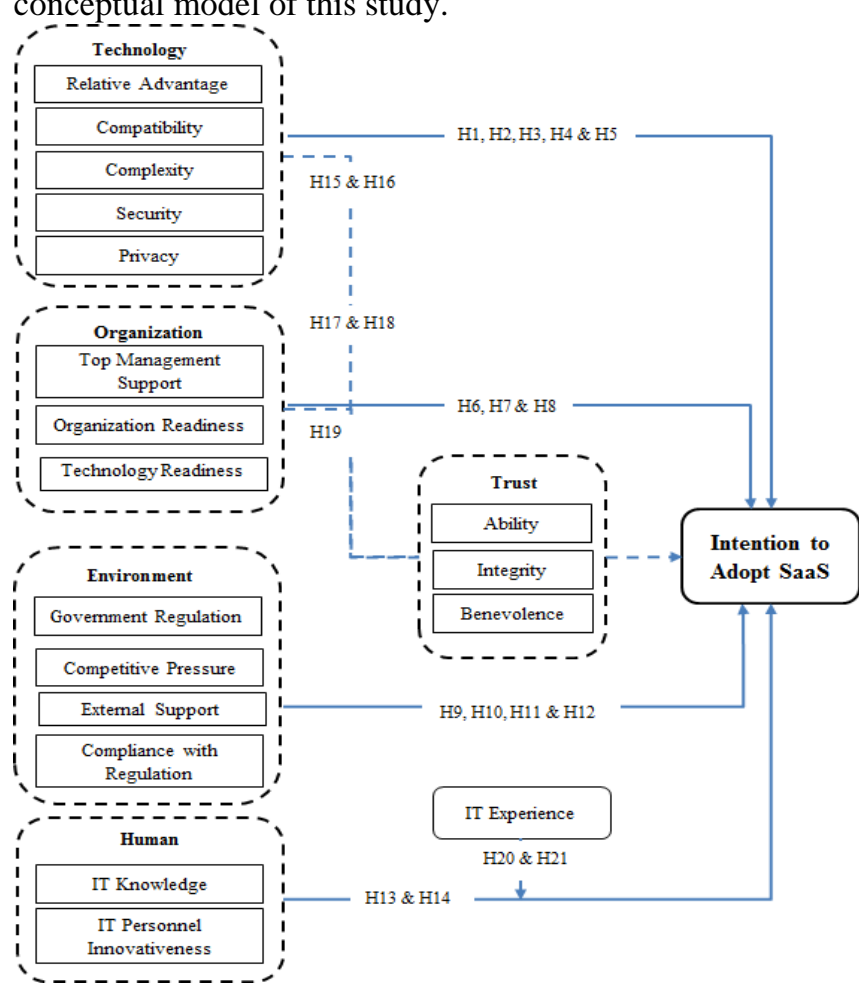

Fig. 1. Proposed conceptual model

\section{HYPOTHESES}

The hypotheses which serve as testable statement are prior assumptions that may be negative or positive, which can be tested statistically for answering the research questions for a comprehensive study. In addition, to provide a reliable result for the proposed model [18]. 
The hypotheses are defined by Sekaran [19], as the statement that can be tested over a logical relationship between one or more numbers of variables. Twenty-One (21) hypotheses have been proposed to be tested in this study which is divided into three categories; main hypotheses with direct relationships, mediating, and moderating relationships as shown in Figure 1.

\section{A. The Technological Dimensions}

Technological Dimensions (TD) refers to the technological factors that affect the organisation's for CC-SaaS intention to adopt [20]. This paper has five (5) technological factors under this dimension used to measure the influence of CC-SaaS intention to adopt, such as Relative Advantage, Compatibility, Complexity, Security and Privacy.

Relative Advantage (RA): refers to extent to which a CC-SaaS technology is perceived as being better than other computing paradigms [21]. RA is one of the key variables of DOI [6]. One of the considerations made organisations in adopting new technology is the perceived benefits and value of such technology. The relative advantage of utilising the cloud its ability to aid organisation in accomplishing it tasks in quicker, cost-efficient, productive and flexible ways [22]. Using CC-SaaS technology, managers can use shared resources [23], as well as pay-as-you-use service by regulating the usage level to reflect the actual organisational needs of the service [24]. Eventually, this will free organisations from unnecessary administration and maintenance of IT infrastructure every year. Thus, when the needs for of CC increases, resources and infrastructure could be scaled up by the cloud user for the satisfaction of the new requirements of the organisation in terms of the servers, processing, storage and bandwidth. Moreover, a simple and unambiguous innovation that can create strategic and operational effectiveness could have a higher impetus for adoption [5]. This means that the advantages of the new technology outweigh that of existing practices and processes [5], such merits could have a positive influence on its adoption. Findings from previous studies revealed that RA has a significant influence on the adoption of new technology [21]. However, it was found insignificant in other studies [22], [25]. The inconsistencies in these studies signal the requirement for further investigations. Hence, the following hypothesis is anticipated:

\section{H1: Relative Advantage (RA) will significantly influence} the intention to adopt $\mathrm{CC}$-SaaS.

Compatibility (CM): refers to extend which the CC-SaaS is perceived to be well-suited with the existing infrastructures, skills, and requirements of an organisation [16], [21]. Generally, compatibility refers to "the degree to which an innovation is perceived as consistent with the existing values, past experiences, and needs of potential adopters " [6], [22]. There is much likelihood that organisations will adopt new technology when it is consistent with their existing work and requirements [22]. In [5], [26] compatibility is highlighted as influencing key factor for any innovation adoption. Hence, the existing literature of IT adoption for various studies have found compatibility as a significant influential factor for new technology adoption. Therefore, previous studies found that compatibility have a significance relationship with

technology adoption [27] while others found insignificant effect [16]. The inconsistencies necessitate further investigation; hence, this hypothesis is constructed:

\section{H2. Compatibility (CM) will significantly influence the intention to adopt CC-SaaS.}

Complexity (CMx): refers to the extent to which relative difficulty is perceived in the understanding and usage of CC-SaaS [21]. In case of IT adoption, CMx it is a time constraint requirement for performing tasks, simplicity of computer integration, data transfer efficiency, the functionality of a system as well as the interface design, etc. This implies that the organisation that found it easier to integrate technology into their organisation operations would be more likely to adopt such technology [5]. It is important noting that in the application of cloud-based solutions challenges also arise through the sharing of organisational well-defined security boundaries and data privacy, and this means instances when no full refinement is made for the multi-tenant environment [5]. Therefore, the deduction can be made from these studies that their relationship between two variable is inverse such as CMx and usefulness, ease of use and adoption intentions [28]. In addition, some studies [13] found that CMx has significant effect, while insignificance in [16], proven to have the needs for further studies. Thus, the current hypothesis is proposed as:

\section{H3. Complexity (CMx) will significantly influence the intention to adopt CC-SaaS.}

Security (Sec): refers to the extent of security measures put in place for the prevention of unauthorized access or alteration to information that has been stored under processing, or in transit for CC-SaaS usage [16]. Security concern has been one of the key reasons various organisation do not intend to use cloud services [22]. The issue of security is seen from many perspectives of IT such as storage, transmission, confidentiality and loss of data, suitability, and breach of privacy in the operations of an organisation [24]. There are high-security concerns in relation to CC-SaaS for the fact that data is placed in an easier way to locate, and sent across many countries via different communication channels, with different data privacy laws and consequently, the chances are that potentially sensitive data could get to snooping eyes of unauthorised persons [24]. Another issue of security concern is the identity management challenges which still unresolved. Kshetri [29] expressed in the cloud adoption decisions among organisations the issues of privacy, security and

availability remain the topmost concerns. As some researchers investigated security and found significance according to [22] and insignificance in [16], [5]. Further, it was stated that security had remained a major obstacle impeding the adoption of CC in many countries [30]. Hence, this hypothesis is proposed as:

H4: Security (Sec) concerns will significantly influence the intention to adopt CC-SaaS. 
Privacy (PRi): refers to the confidentiality of data and information provided by CC-SaaS, where the only authorised person can access it [31]. In relation to privacy, when the third party stored and managed information, user organisations lost full control over such information. Therefore, the risk level of data confidentiality increases, and eventually privacy might be breached [22], thus, privacy has remained one of the key issues of concerns among many organisations intending to apply cloud for the storage of their data and applications. Therefore, some studies revealed that privacy has a significant effect on the adoption of new technology [22]. Thus, a hypothesis is proposed as follows:

H5: Privacy (PRi) concerns will significantly influence the intention to adopt $\mathrm{CC}$-SaaS.

\section{B. The Organisational Dimensions}

Organisational Dimensions (OD) refers to the provision of resource management, goal specifying and commitment of decision-makers who influence the adoption of SaaS-based CC adoption [20]. In this study, there are three (3) Organisational factors under this dimension used to measure the influence of intention to adopt CC-SaaS, e.g. Organisational Readiness, Technological Readiness and Top Management Support.

Top Management Support (TMS): is considered here as to the provision of resource management, goal specification and commitment of decision-makers who influence the intention to adopt CC-SaaS [16], [20]. Extant literature on IT adoption has given cognisance on the role of TMS in initiating, implementing and adopting various information technologies [32]. It was explained in Salwani et al. [33] that TMS reflects the perceptions and actions undertake by top officials in ensuring that technological innovation becomes useful in the creation of values for the organisation. Such values are resources commitment and optimal management, ensures long-term vision, greater assessments of self-efficacy of individual and favourable organisational climate values, as well as support to overcome barriers and change resistance [24]. Besides, TMS plays a critical role in the adoption of CC through the guidance it offers in resource allocation, service integration, and process re-engineering [5]. Also, an important role is playing by TMS in the level of new technology acceptance for the organisational [22]. The preceding review implied that support from top management is critical in the execution of change, especially relating to cloud adoption among organisations. Hence, this study hypothesises TMS as:

H6: Top management support (TMS) will significantly influence the intention to adopt CC-SaaS.

Organisational Readiness (OR): is considered as the determination of technological readiness and financial resources that are necessary towards the adoption of CC-SaaS [20]. Organisational readiness is defined by Tan et al. [34] as the perception and evaluation of managers of the extent of their belief relating to the possession of necessary awareness, resources, governance and commitment towards the adoption of new technology. The OR has broadly considered having two dimensions; technological and financial readiness [24]. Gangwar et al., [24] contend that adoption of CC is more likely among organisations that possess expertise in employees and effective infrastructure, as well as financial support. For the intention to adopt CC-SaaS in Iraqi's organisations, there is the need for competent IT staff, adequate infrastructure to support computer network as well as a highly relied Internet connection for supporting and troubleshooting the services. This is necessary because unreliable Internet connection will likely lead to problem or disruption of services, and eventually lead to the implementations failure of the CC [13]. Therefore, following these arguments, the hypothesis below is proposed.

H7: Organisational Readiness (OR) will significantly influence the intention to adopt CC-SaaS.

Technology Readiness (TR): is considered the degree of IT human resources and IT infrastructures readiness that affects the decision of the organisation towards the adoption of CC-SaaS technology [12], [20]. In short, technological infrastructure is the network technologies, IT appliances and organisational structure, which offers a platform for building CC applications. Skills and knowledge are sourced form IT human resources for the implementation of IT applications related to CC [35]. If the organisation acquired necessary infrastructure and technical competence in relation to CC services such could become part of its value chain activities [36]. Alkhariji et al., [37], emphasised that negative impact for CC adoption is associated with the problem of existing organisation's infrastructure. Therefore, the preparedness of organisation on the intention to adopt CC-SaaS is assessed through technological readiness. With these considerations, this hypothesis is proposed:

H8. Technology Readiness (TR) will significantly influence the intention to adopt CC-SaaS.

\section{The Environmental Dimensions}

Environment Dimension (ED) is considered the external factors that affect the intention to adopt CC-SaaS technology [20]. In this study, there are four (4) Environmental factors under this dimension used to investigate the influence on CC-SaaS intention to adopt, such as Governmental Regulation, Competitive Pressure, External Support and Compliance with regulation.

Government Regulation (GR): is considered as the set of regulation, policies and initiatives support designed by the authority guide the decisions towards the adoption CC-SaaS [10]. Technological innovations are considered as important strategic assets possess by countries, as well as the orientations available that can help organisations to achieve better performance in terms of service innovation assists organisation in the adoption of technological innovation through the promotion-specific services associated with higher success in the international marketplace [38]. Moreover, GR is considered as support offered by a government to the organisation for encouraging IT assimilation in innovative ways [5]. This signifies that existing laws and regulations could have a potentially critical impact in adopting new technologies. Regulations introduced by the government could encourage or discourage the organisation from the adoption of CC. 
In Canada and Europe, for instance, there has been a debate on the use of cloud resources supplied by US-based providers in line with US Patriotic Act [39]. Therefore, the Iraqi government needs to ensure that the regulatory environment is conducive for the effective use of CC services, especially for services offered by companies in the international market. In addition, there is also a legal aspect which relates to the privacy and protection of data. Therefore, it is imperative to devise means for understanding the perceptions with regards existing rules and regulations as well as their enforcement for the protection of the users of cloud services. Thus, the hypothesis is proposed:

\section{H9. Government Regulatory (GR) will significantly} influence the intention to adopt CC-SaaS.

Competitive Pressure (CP): is considered here as the extent of pressure faced by an organisation from citizens regarding the delivery of service [10]. Innovation diffusion literature has identified CP as a key driver in technology diffusion [5]. This implied that organisations could gain benefits in terms of enhanced operational efficiency and real-time access to accurate data through the adoption of CC [5]. Further, even in the early stages of technology innovation research, competitive pressure has been recognised to be an effective motivator [24]. Generally, competition within an organisation is expected to have significant impact on the IT adoption, especially when such technology has a direct effect on the competition, and it is considered strategically necessity organisation can only favourably compete through the adoption of new technologies [24]. This fact is also applicable within CC-SaaS context; hence, the hypothesis is set as:

H10. Competitive pressure (CP) will significantly influence the intention to adopt CC-SaaS.

External Support (ES): is considered as the supports from CC-SaaS providers, training partners or relative associations which influences organisation with regards to the intention to adopt CC-SaaS [10], [20]. External support has been regarded here as support from the side of a cloud provider that will enable the organisation in meeting its requirements. Literature, documents that ES emerged from the previously conducted interviews with IT experts [22]. Majority of the experts interviewed through exploratory study made it clear that there is a need for 24/7 support from the side of the cloud provider to enable them to meet their needs. Thus, there is a need for an empirical study about ES from the perception of CC-SaaS intention to adopt, more specifically in Iraq. Hence, it is hypothesized below that:

H11: External support (ES) will significantly influence the intention to adopt CC-SaaS.

Compliance with Regulation (CR): refers to the concerns for the fact that no existing governmental rules or regulations that can support an organisation that intends to adopt CC-SaaS when data is breach [40]. CR issues can hinder an organisation from cloud technology adoption. This could be possible due to lack of IT regulations and standards that can provide support to organisations in the instances of breaches of cloud privacy and securities [22]. Alassafi et al.,[41] and Marston et al., [23] have the same view with Gartner, which stated that regulatory compliance is one critical risk factors

government need to be aware of before the adoption of cloud technology, this should be done even when the control is totally held by the service provider [40]. As the CC-SaaS providers can store data in another country without the consent of the user, which may lead to compliance and privacy concern [22]. This risk is possible giving the fact that no existing regulations or directives from the government to protect the organisation against data breach [40]. Therefore, this study believes that the organisation is more likely to adopt CC-SaaS when existing regulations are being complied. Hence, the hypothesis is proposed as follows:

H12: Compliance with regulations (CR) will significantly influence the intention to adopt CC-SaaS.

\section{The Human Dimensions}

Human Dimension (HD) refers to the human factors influencing organisational intention towards the adoption of CC-SaaS technology [42]. In this study, there are two (2) Human factors under this dimension used to measure the influence of human factors on CC-SaaS adoption intention, such as IT Knowledge and IT personnel Innovativeness.

IT Knowledge (IK): refers to the ability and technical skills of IT managers to foresee and leverage CC-SaaS towards the organisational goal [43]. The technical capabilities of IT personnel, their competencies and knowledge will be also likely to impact on the organisation in the adoption of an IT innovation [13]. Thus, when IT personnel possess the requisite knowledge, innovation and skills with regards to the adoption of CC, such organisation could certainly have greater confidence in the assimilation process. Thus, the hypothesis is proposed as:

H13: IT Knowledge (IK) will significantly influence the intention to adopt CC-SaaS.

IT Personnel Innovativeness (IPI): Refers to an individual's curiosity to try out CC-SaaS and apply IT in novel ways to support service delivery to the organisation [44]. Agarwal and Prasad [45] described personal innovativeness as a propensity to take a risk that could arise in some individuals but not in others.

Such that these individuals could be willing to take such risks by trying new things and have the disposure to deal with greater levels of uncertainty [46]. As mention by Rogers [6], in the innovation diffusion research, the personal innovativeness construct has been extensively discussed.

In both theoretical and empirical studies, personal innovativeness has been considered as important variables in the process of adoption new innovation. Empirical literature documents the direct positive influence of personal innovativeness values [47]. Further, studies such as that of Leonard-Barton and Deschamps [48] considered personal innovativeness as the receptivity of individual toward change, which was found to be significantly influential factors for successful adoption of innovation and technology. This evidence implied that individual's receptivity in terms of risk-taking through testing new things would likely lead to a stronger wish for innovation that could lead to the production of technological goods. 
Consequently, it is expected here that those individuals that take chances and explore new approaches of using things would be more likely to be motivated and become the first to develop intention towards the adoption of CC-SaaS. Thus, the hypothesis is proposed as:

H14: IT Personnel Innovativeness (IPI) will significantly influence the intention to adopt CC-SaaS.

\section{E. Mediating Hypothesis}

In this study, the trust dimension served as a mediating variable in respect to three characteristics. The hypotheses for the mediating variable are formed with regards to the ability, integrity and benevolence for trust dimensions. Moreover, trust can be referred to as the level of confidence that CC-SaaS providers are reliable and SaaS-based functions as expected [49]. The most important security issues in CC are trust, integrity, availability, authentication and authorisation, and confidentiality [50]. Trust is beyond just the trusting of the cloud provider, and it encompasses the issue of distrusting the technology and its capabilities in providing the quality service as well as the absence of interruption or loss of data in the process of the service provision. Therefore, in such a critical situation, the decision-makers of the organisation expect a certain level of assurances [51]. Additionally, the CC provider needs to create a level playing field in such a way that some reasonable assurances is given to the users, such as assurances with regards to the ability to provide the service and relevant user support by service providers, it also includes the integrity in securing sensitive information and benevolence in operating the service in the interest of users [51]. Therefore, the trust as a factor has three dimensions such as ability, integrity and benevolence.

\section{1) Ability as a Mediator}

Ability (Abi) refers to the belief that CC-SaaS providers have the knowledge and technical skill that improve the organisation's performance [49]. It is a known fact that individuals and organisations vary in abilities; while an individual or an organisation may be able to perform some excellently in some tasks or domain, same individual or organisation could have lower ability in relation others tasks and fields [49]. In relations to CC adoption intention, the ability is described as a set of characteristics, technical skills and competencies that aid an organisation in exerting influence over some specific domain [49]. Consequently, a certain level of trust is needed for encouraging the organisation to execute an action towards the adoption of CC. The trust threshold level is reached when enough evidence exists that provide some reasonable assurances to decision-makers on ability service providers [51]. Thus, this study hypothesises the way in which an organisation perceives service provider's ability in terms of complexity and compatibility of technology influence CC-SaaS intention to adopt where such ability is relevant. Hence, these hypotheses are drafted as follows:

H15: Ability (Abi) will mediate the relationship between compatibility (CM) and the intention to adopt CC-SaaS

H16: Ability (Abi) will mediate the relationship between complexity (CMx) and the intention to adopt CC-SaaS

\section{2) Integrity as a Mediator}

Integrity (Int) refers to the belief that CC-SaaS providers are honest, keep promises and can do what is right [52]. Trust is ensured through the establishment of effective security policies and protections on data access by unauthorised persons [53]. Hence, the CC industry needs to ensure privacy and security are adequately provided mainly for users' sensitive information while utilising the services. Further, Kshetri [29] expressed that security and privacy issues are considered among the key concerns hindering organisations in the decision towards the adoption of the cloud. For the fact that CC services are a new concept in relation to other Internet services, there is the need to explore the integrity issues concerning this technology [54], this is to ensures that security and privacy concerns of the organisation are taken care of so as to uphold their willingness to adopt the CC-SaaS. Thus, following these arguments, the hypotheses below are proposed as:

H17: Integrity (Int) will mediate the relationship between security (Sec) and the intention to adopt CC-SaaS

\section{H18: Integrity (Int) will mediate the relationship between privacy (PRI) and the intention to adopt CC-SaaS}

\section{3) Benevolence as a Mediator}

Benevolence (Ben) refers to the belief that CC-SaaS providers' motives, intentions and concerned about the interests of an organisation [49], [52]. Benevolence has been counted as one of the key five pillars applied in the definition of trust [55]. Following the early trust theory, trust as a concept has been divided into several clusters with benevolence considered among the most common of those categories [56].

Benevolence exists through the presence of interaction between at least two, and these are the trustee and the trustor. In this study, the two parties are CC-SaaS providers and the organisation willing to adopt the cloud service [56]. The organisations are looking for cues to guide their associations and interaction with technology, that can be trusted enough to assist them in the effective and efficient delivery of the services.

In this, organisation expect certain behaviour like such human from technology, i.e. such that the technology would behave in in a deceptive manner them

or malfunction at their own expense [57]. A perception by organisations that technology will assist them in achieving their goals and will work in their best interest, such could lead to a higher likelihood to develop intention for the adoption of technology. Consequently, Top management support would likely influence the intention towards the adoption of CC-SaaS among organisations, especially in anticipation of a better service from vendors. Thus, this hypothesis is proposed:

H19: Benevolence (B) will mediate the relationship between Top Management Support (TMS) and the intention to adopt CC-SaaS 


\section{F. Moderating Hypothesis}

The IT Experience is proposed as the moderating variable between IT Knowledge and IT Personnel Innovativeness, where two hypotheses for moderating variables are generated. IT Experience (ITE) has been described as the degree of a user's experience in using technologies or similar technologies in the past [58]. It is argued here that prior experience in using technology or similar technologies would likely influence the user's intention towards new technology adoption. Such that when the user had positive experiences in using CC technology in the past, such user would be more likely to develop a positive temperament towards forming an intention for the adoption and use CC or otherwise would not develop such intention or involve in actual usage [59]. Users with more IT experience will find that the risk associated with the adoption of the technology will be low, and thus it improves their perception of usefulness and motivates their actual usage over time [60]. Therefore, the existence of personnel experience may reveal the knowledge and innovativeness of an individual towards CC-SaaS. In this study, the IT experience is proposed to moderate the effect of IT knowledge and personnel innovativeness on the intention to adopt CC-SaaS. Thus, the hypotheses are as follows:

H20: IT Experience (ITE) will moderate the relationship between IT knowledge (IK) and the intention to adopt CC-SaaS

H21: IT Experience (ITE) will moderate the relationship between IT personnel innovativeness (IPI)and the intention to adopt CC-SaaS

\section{RESULT AND DISCUSSION}

The factors used for developing the conceptual model are selected based on high frequency from the literature influence according to Wymer and Regan [61]. To validate the factors for the influential effect for CC-SaaS intention to adopt are validated by the experts which are selected based on the criteria proposed by Sarif et al.,[62] and Norfiza [63] That is, the expert must have a $\mathrm{PhD}$ in computer science or any related area such as information system; have at least five (5) years' experience in the field related to academic research and being a researcher in the field. Further, the SPSS statistical analysis software is used for the analysis of the experts' responses to determine whether the validation form the experts is statistically different from the known influence of the hypothesized effect of the factor discovered from the literature. Therefore, one sample T-Test which is parametric test is used.

\section{A. Sample T-Test}

The test of the selected and validated factors are compared against a test value, which is compared the differences in a mean experts' scores for the factors of continuous level of interval or ratio and normally distributed data. The test compared the mean of a single factor to a predetermined value to find out if the sample means of the factor is significant for the influence of CC-SaaS use, adoption or intention to adopt. Table I presented the T-test result run from SPSS showing the one sample statistics for fourteen selected and validated factors. The result of the test revealed that compatibility, security, privacy, top management support organisation readiness and IT knowledge have the smallest or almost zero standard deviations. Their result can be interpreted as most or very significant factors that influence the CC-SaaS as their values are close to the mean of the statistical data set. Therefore, their t-test cannot be computed as they clearly indicated the significant effect from their values of standard deviation as zero, which is same with their standard error values. In addition, the other factor needs to undergo the t-test due to the variance in their standard deviation which is non-zero values.

Table-I. One-Sample Statistics

\begin{tabular}{lcccc}
\hline Factors & N & Mean & Std. Deviation & Std. Error Mean \\
\hline Relative Advantage & 5 & 2.80 & .447 & .200 \\
Compatibility & 5 & 3.00 & $.000^{\mathrm{a}}$ & .000 \\
Complexity & 5 & 2.40 & .894 & .400 \\
Security & 5 & 3.00 & $.000^{\mathrm{a}}$ & .000 \\
Privacy & 5 & 3.00 & $.000^{\mathrm{a}}$ & .000 \\
Top Management Support & 5 & 3.00 & $.000^{\mathrm{a}}$ & .000 \\
Technology Readiness & 4 & 2.00 & 1.155 & .577 \\
Organisation Readiness & 5 & 3.00 & $.000^{\mathrm{a}}$ & .000 \\
Government Regulation & 5 & 1.60 & .894 & .400 \\
Competitive Pressure & 5 & 1.80 & .837 & .374 \\
Compliance with Regulation & 5 & 2.80 & .447 & .200 \\
External Support & 5 & 2.80 & .447 & .200 \\
IT Personal Innovativeness & 5 & 2.80 & .447 & .200 \\
IT Knowledge & 5 & 3.00 & $.000^{\mathrm{a}}$ & .000 \\
\hline
\end{tabular}

a. $t$ cannot be computed because the standard deviation is 0 .

Basically, if the standard deviation is on the average or large meaning that the values of the factors are far away from the hypothesized influence of the factor. Hence further investigation is needed for the actual influence of the factor using T-test. Thus, the t-test is run on the relative advantage, complexity, technology readiness, government regulation, competitive pressure, compliance with regulation, external support and IT personnel innovativeness as shown in Table II. The result confirmed other factors except for technology readiness, government regulation and competitive pressure which have less than one-third of the t-value (3.464, 4.000 and 4.811). With a $95 \%$ confidence interval of the differences relative advantage, complexity, compliance with regulation, external support and IT personnel innovativeness are significant with a less. 
The result confirmed the expert validation in such a way that all factors influence the CC-SaaS intention to adopt except four factors mentioned. The p-value of non-significance factors is high, meaning that they have less or no significant influence on the adoption of CC-SaaS. Technology readiness, government regulation and competitive pressure factors have the highest p-value as $0.41,0.16$ and 0.09 . Although some the factors with higher $\mathrm{p}$-value have a high frequency from the literature, the statistical analysis rejected them as they have insignificant values.

Table-II: One-Sample Test

\begin{tabular}{|c|c|c|c|c|c|c|}
\hline \multirow[b]{3}{*}{ Factors } & \multicolumn{6}{|c|}{ Test Value $=0$} \\
\hline & \multirow[b]{2}{*}{$\mathbf{t}$} & \multirow[b]{2}{*}{ df } & \multirow[b]{2}{*}{ Sig. (2-tailed) } & \multirow{2}{*}{$\begin{array}{c}\text { Mean } \\
\text { Difference }\end{array}$} & \multicolumn{2}{|c|}{$\begin{array}{l}\text { 95\% Confidence Interval of } \\
\text { the Difference }\end{array}$} \\
\hline & & & & & Lower & Upper \\
\hline Relative Advantage & 14.000 & 4 & .000 & 2.800 & 2.24 & 3.36 \\
\hline Complexity & 6.000 & 4 & .004 & 2.400 & 1.29 & 3.51 \\
\hline Technology Readiness & 3.464 & 3 & .041 & 2.000 & .16 & 3.84 \\
\hline Government Regulation & 4.000 & 4 & .016 & 1.600 & .49 & 2.71 \\
\hline Competitive Pressure & 4.811 & 4 & .009 & 1.800 & .76 & 2.84 \\
\hline Compliance with Regulation & 14.000 & 4 & .000 & 2.800 & 2.24 & 3.36 \\
\hline External Support & 14.000 & 4 & .000 & 2.800 & 2.24 & 3.36 \\
\hline IT Personal Innovativeness & 14.000 & 4 & .000 & 2.800 & 2.24 & 3.36 \\
\hline
\end{tabular}

Due to the experts' assessments and statistical analysis of their validation, the final factors that are expected to significantly influence the intention to adopt CC-SaaS are shown in Table III. The factors are expected to represent the final conceptual model which will be used for the empirical analyses of hypotheses testing for the final model of CC-SaaS intention to adopt.

Table-III: Significant Factors

\begin{tabular}{|l|c|}
\hline Factors & $\begin{array}{c}\text { Std. } \\
\text { Deviation }\end{array}$ \\
\hline Relative Advantage & .447 \\
\hline Compatibility & $.000^{\mathrm{a}}$ \\
\hline Complexity & .894 \\
\hline Security & $.000^{\mathrm{a}}$ \\
\hline Privacy & $.000^{\mathrm{a}}$ \\
\hline Top Management Support & $.000^{\mathrm{a}}$ \\
\hline Organisation Readiness & $.000^{\mathrm{a}}$ \\
\hline Compliance with Regulation & .447 \\
\hline External Support & .447 \\
\hline IT Personal Innovativeness & .447 \\
\hline IT Knowledge & $.000^{\mathrm{a}}$ \\
\hline
\end{tabular}

\section{CONCLUSION}

This paper presents a detail about the conceptual model and hypotheses development presented in this study. The model of CC-SaaS adoption intention is shown with a direct relationship of four dimensions covering technology, organisation, environment and human perspectives. Besides, the trust dimension is proposed to mediate the relationships between some factors of technological, organisational dimensions and CC-SaaS-based adoption intention. Moreover, IT experience is suggested to moderate the relationship between IT knowledge and IT personnel innovativeness as the independent variables, and the dependent variable which is the intention to adopt CC-SaaS. The discussions for relationships among dependent variables, independent variables, mediating variable, and moderating variable are also presented. In addition, the research hypotheses are explained in detail which are proposed in line with the proposed conceptual model of this study. In addition, this study is expanded for the confirmation of the selected factors by experienced academic and industrial experts. Their validated or confirmation values are statistically analysed using SPSS for t-test analysis. In the future, a model with its influential hypothesis will be formulated for the empirical investigation of these selected factors. In the future, the study will describe the adapted research methodology and actualised the empirical evaluation of the proposed model.

\section{REFERENCES}

1. D. Puthal, B. P. S. Sahoo, S. Mishra, and S. Swain, "Cloud computing features, issues, and challenges: a big picture," in 2015 International Conference on Computational Intelligence and Networks, 2015, pp. 116-123.

2. H. Abid, L. T. T. Phuong, J. Wang, S. Lee, and S. Qaisar, "V-Cloud: vehicular cyber-physical systems and cloud computing," in Proceedings of the 4th International Symposium on Applied Sciences in Biomedical and Communication Technologies, 2011, p. 165.

3. M. Anshari, Y. Alas, and L. S. Guan, "Developing online learning resources: Big data, social networks, and cloud computing to support pervasive knowledge," Educ. Inf. Technol., vol. 21, no. 6, pp. 1663-1677, 2016.

4. T. Clohessy, T. Acton, L. Morgan, K. Conboy, and T. Clohessy, "The times they are a-changin for ICT service provision: A cloud computing business model perspective," in 24th European Conference in Information Systems (ECIS), 2016, pp. 1-15.

5. T. Oliveira, M. Thomas, and M. Espadanal, "Assessing the determinants of cloud computing adoption: An analysis of the manufacturing and services sectors," Assess. Determ. cloud Comput. Adopt. An Anal. Manuf. Serv. Sect., vol. 51, no. 5, pp. 497-510, 2014.

6. E. M. Rogers, Diffusion of innovations. Simon and Schuster, 2010.

7. S.-L. Chen, J.-H. Chen, and Y. Lee, "A comparison of competing models for understanding industrial organization's acceptance of cloud services," Sustainability, vol. 10, no. 3, p. 673, 2018.

8. T. Oliveira, R. Martins, S. Sarker, M. Thomas, and A. Popovič, "Understanding SaaS adoption: The moderating impact of the environment context,” Int. J. Inf. Manage., vol. 49, pp. 1-12, 2019.

9. B. Yeo and D. Grant, "Predicting service industry performance using decision tree analysis,” Int. J. Inf. Manage., vol. 38, no. 1, pp. 288-300, 2018.

10.C.-Y. Chiu, S. Chen, and C.-L. Chen, “An integrated perspective of TOE framework and innovation diffusion in broadband mobile applications adoption by enterprises,” Int. J. Manag. Econ. Soc. Sci., vol. 6, no. 1, pp. 14-39, 2017

11.Y. Liang, G. Qi, K. Wei, and J. Chen, "Exploring the determinant and influence mechanism of e-Government cloud adoption in government agencies in China," Gov. Inf. Q., vol. 34, no. 3, pp. 481-495, 2017.

12.F. Mohammed, O. Ibrahim, and N. Ithnin, "Factors influencing cloud computing adoption for e-government implementation in developing countries: Instrument development,” J. Syst. Inf. Technol., vol. 18, no. 3, pp. 297-327, Aug. 2016 
13.H. Sallehudin, R. C. Razak, and M. Ismail, "Determinants and impact of cloud computing implementation in the public sector," J. Adv. Inf. Technol. Vol, vol. 7, no. 4, pp. 245-251, 2019.

14.M. M. Yusof, J. Kuljis, A. Papazafeiropoulou, and L. K. Stergioulas, “An evaluation framework for Health Information Systems: human, organization and technology-fit factors (HOT-fit)," Int. J. Med. Inform., vol. 77, no. 6, pp. 386-398, 2008.

15.S. Schneider and A. Sunyaev, "Determinant factors of cloud-sourcing decisions: reflecting on the IT outsourcing literature in the era of cloud computing," J. Inf. Technol., vol. 31, no. 1, pp. 1-31, 2016.

16.T. Lynn, X. Liang, A. Gourinovitch, J. P. Morrison, G. Fox, and P. Rosati, "Understanding the determinants of cloud computing adoption for high performance computing," in Proceedings of the 51st Hawai International Conference on System Sciences, 2018, pp. 3894-3903.

17.M. A. Wahsh and S. D. Jaspaljeet, "An investigation of factors affecting the adoption of cloud computing for e-government implementation," 2015 IEEE Student Conf. Res. Dev. SCOReD 2015, vol. 10, no. 23, pp. 323-328, 2015.

18.H. M. Sabi, F. M. E. Uzoka, K. Langmia, and F. N. Njeh, "Conceptualizing a model for adoption of cloud computing in education,” Int. J. Inf. Manage., vol. 36, no. 2, pp. 183-191, 2016.

19.U. Sekaran, S. Uma, R. Bougie, U. Sekaran, and R. Bougie, Research methods for business: A skill building approach, (4th ed.). Chichester, United Kingdom: John Wiley, 2003.

20.A. Alhammadi, C. Stanier, and A. Eardley, "The determinants of cloud computing adoption in Saudi Arabia," Comput. Sci. Inf. Technol. (CS IT), vol. 5, no. 14, pp. 55-67, 2015.

21.M. Stieninger, D. Nedbal, W. Wetzlinger, G. Wagner, and M. Erskine, "Factors influencing the organizational adoption of cloud computing. A survey among cloud workers," Int. J. Inf. Syst. Proj. Manag., vol. 6 no. 1, pp. 5-23, 2018.

22.N. Alkhater, R. Walters, and G. Wills, "An empirical study of factors influencing cloud adoption among private sector organisations," Telemat. Informatics, vol. 35, no. 1, pp. 38-54, 2018.

23.S. Marston, Z. Li, S. Bandyopadhyay, J. Zhang, and A. Ghalsasi, "Cloud computing - The business perspective," Decis. Support Syst., vol. 51, no. 1, pp. 176-189, 2011.

24.H. Gangwar, H. Date, and R. Ramaswamy, "Developing a cloud-computing adoption framework," Glob. Bus. Rev., vol. 16, no. 4 pp. 632-651, 2015.

25.A. Gutierrez, E. Boukrami, and R. Lumsden, "Technological, organisational and environmental factors influencing managers' decision to adopt cloud computing in the UK," J. Enterp. Inf. Manag. vol. 28, no. 6, pp. 788-807, 2015.

26.C. A. Mora-Monge, A. Azadegan, and J. Teich, "Effective benchmarking of innovation adoptions," Benchmarking An Int. J., 2010.

27.S. Başaran and G. O. Hama, "Exploring faculty members'views on adoption of cloud computing in education," in Proceedings of the International Scientific Conference. Volume V, 2018, vol. 227, p. 237.

28.K. K. Y. Kuan and P. Y. K. Chau, "A perception-based model for EDI adoption in small businesses using technology-organization-environment framework," Inf. Manag., vol. 38, no. 8, pp. 507-521, 2001.

29.N. Kshetri, "Privacy and security issues in cloud computing: The role of institutions and institutional evolution," Telecomm. Policy, vol. 37, no. 4-5, pp. 372-386, 2013.

30.M. Ali, S. U. Khan, and A. V Vasilakos, "Security in cloud computing: Opportunities and challenges,” Inf. Sci. (Ny)., vol. 305, pp. 357-383, 2015.

31.N. Alkhater, G. Wills, and R. Walters, "Factors influencing an organisation's intention to adopt cloud computing in Saudi Arabia," in 2014 IEEE 6th international conference on cloud computing technology and science, 2014, pp. 1040-1044.

32.R. K. Singh, "Analyzing the factors for VMI implementation: A framework,” Glob. Bus. Rev., vol. 14, no. 1, pp. 169-186, 2013.

33.M. Intan Salwani, G. Marthandan, M. Daud Norzaidi, and S. Choy Chong, "E-commerce usage and business performance in the Malaysian tourism sector: empirical analysis," Inf. Manag. Comput. Secur., vol. 17, no. 2, pp. 166-185, 2009.

34.J. Tan, K. Tyler, and A. Manica, "Business-to-business adoption of eCommerce in China,” Inf. Manag., vol. 44, no. 3, pp. 332-351, 2007.

35.S. Author, T. Authors, N. America, and W. Society, "APA Reference Lis Examples,” APA Ref. List Examples B., pp. 2006-2008, 2006.

36.F. Alharbi, A. Atkins, and C. Stanier, "Understanding the determinants of cloud computing adoption in Saudi healthcare organisations," Complex Intell. Syst., vol. 2, no. 3, pp. 155-171, 2016.

37.A. Alkraiji, T. Jackson, and I. Murray, "Barriers to the widespread adoption of health data standards: an exploratory qualitative study in tertiary healthcare organizations in Saudi Arabia," J. Med. Syst., vol. 37, no. 2, p. 9895, 2013.

38.V. Ratten, "Service innovations in cloud computing: A study of top management leadership, absorptive capacity, government support, and learning orientation,” J. Knowl. Econ., vol. 7, no. 4, pp. 935-946, 2016

39.A. N. Tashkandi and I. M. Al-Jabri, "Cloud computing adoption by higher education institutions in Saudi Arabia: an exploratory study," Cluster Comput., vol. 18, no. 4, pp. 1527-1537, Dec. 2015.

40.M. Alassafi, A. Alharthi, A. Alenezi, R. Walters, and G. Wills, "Investigating the security factors in cloud computing adoption: Towards developing an integrated framework," J. Internet Technol. Secur. Trans., vol. 5, no. 2, 2016

41.M. O. Alassafi, A. Alharthi, R. J. Walters, and G. B. Wills, "Security risk factors that influence cloud computing adoption in Saudi Arabia government agencies," in 2016 International Conference on Information Society (i-Society), 2016, pp. 28-31.

42.M. G. R. Alam, A. K. M. Masum, L.-S. S. Beh, and C. S. Hong, "Critical factors influencing decision to adopt human resource information system (HRIS) in hospitals,” PLoS One, vol. 11, no. 8, p. e0160366, 2016.

43.R. J. Nathan, V. Victor, C. L. Gan, and S. Kot, "Electronic commerce for home-based businesses in emerging and developed economy," Eurasian Bus. Rev., pp. 1-21, 2019.

44.Z. Shao and Q. Huang, "Transformational leadership and IS extended use-the mediating role of job autonomy and moderating role of IT nnovativeness.," in PACIS, 2018, p. 9.

45.R. Agarwal and J. Prasad, "A conceptual and operational definition of personal innovativeness in the domain of information technology," Inf. Syst. Res., vol. 9, no. 2, pp. 204-215, 1998.

46.G. C. Bruner, P. J. Hensel, and K. E. James, "Marketing scales handbook: A compilation of multi-item measures for consumer behavior \& advertising (Vol. 4)," Chicago, IL: Thomson South-Western, 2005.

47.J. B. Hartman and Y. M. Samra, "Impact of personal values and innovativeness on hedonic and utilitarian aspects of web use: An empirical study among United States teenagers," Int. J. Manag., vol. 25, no. 1, p. 77, 2008.

48.D. Leonard-Barton and I. Deschamps, "Managerial influence in the implementation of new technology," Manage. Sci., vol. 34, no. 10, pp. 1252-1265, 1988

49.H. Svare, A. H. Gausdal, and G. Möllering, "The function of ability, benevolence, and integrity-based trust in innovation networks," Ind Innov., pp. 1-20, 2019.

50.H. Karajeh, M. Maqableh, and R. Masa'deh, "Privacy and security issues of cloud computing environment," in Proceedings of the 23rd IBIMA Conference Vision, 2020, pp. 1-15

51.J. K. Adjei, "The role of social media in national discourse and mobilization of citizens," in 2016 International Conference on Collaboration Technologies and Systems (CTS), 2016, pp. 559-563.

52.H. Hallikainen and T. Laukkanen, "National culture and consumer trust in e-commerce,” Int. J. Inf. Manage., vol. 38, no. 1, pp. 97-106, 2018.

53.D. Zissis and D. Lekkas, "Addressing cloud computing security issues," Futur. Gener. Comput. Syst., vol. 28, no. 3, pp. 583-592, 2012.

54.A. Tarhini, R. Masa'deh, A. Al-Badi, M. Almajali, and S. H. Alrabayaah, "Factors influencing employees' intention to use cloud computing," J. Manag. Strateg., vol. 8, no. 2, pp. 47-62, 2017.

55.R. C. Mayer, J. H. Davis, and F. D. Schoorman, "An integrative model of organizational trust,” Acad. Manag. Rev., vol. 20, no. 3, pp. 709-734, 1995.

56.G. Warner-Søderholm et al., "Who trusts social media?," Comput. Human Behav., vol. 81, pp. 303-315, 2018.

57.N. K. Lankton, D. H. McKnight, and J. Tripp, "Technology, humanness, and trust: Rethinking trust in technology,” J. Assoc. Inf. Syst., vol. 16, no. 10, p. 1, 2015

58.Y. Alshamaila, S. Papagiannidis, and F. Li, "Cloud computing adoption by SMEs in the north east of England: A multi-perspective framework," J. Enterp. Inf. Manag., vol. 26, no. 3, pp. 250-275, 2013.

59.P. Ambrose, "An empirical investigation of cloud computing for personal use,” MWAIS 2010 Proc., vol. 24, pp. 1-5, 2010.

60.S. Tripathi, "Moderating effects of age and experience on the factors influencing the actual usage of cloud computing," J. Int. Technol. Inf. Manag., vol. 27, no. 2, pp. 121-158, 2018.

61.S. A. Wymer and E. A. Regan, "Factors influencing e-commerce adoption and use by small and medium businesses," Electron. Mark., vol. 15, no. 4, pp. 438-453, 2005.

62.S. M. Sarif, N. Ibrahim, and N. Shiratuddin, "Design model of computerized personal decision aid for youth: An expert review," in AIP Conference Proceedings, 2016, vol. 1761, no. 1, p. 20097.

63.I. Norfiza, "Conceptual design model for youth personal decision." Universiti Utara Malaysia, 2017.

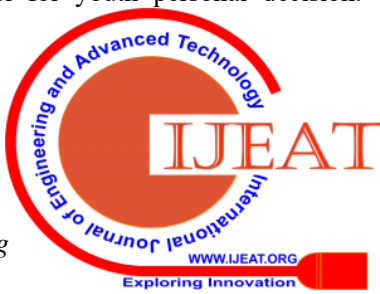




\section{AUTHORS PROFILE}

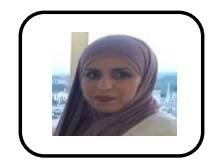

Hiba Jasim Hadi, Received master's degree in Information Technology, from the School of Computing, Universiti Utara Malaysia, in 2016. She is currently pursuing the Ph.D. degree in Information Technology at Universiti Utara Malaysia. Her expertise are data mining, m-learning, e-government and cloud computing.

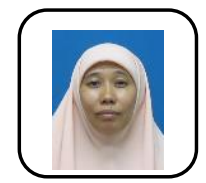

Dr. Nafishah Othman: Obtained her master's degree in Information Technology and Manufacture from University of Hull, United Kingdom (1993), and Ph.D. Information Technology (2014) at Universiti Utara Malaysia. Now is currently a Senior Lecturer at School of Computing, Universiti Utara Malaysia. Her research expertise are teleworking, ICT policy and social impact, e-government.

Prof. Dr Wan Rozaini Sheik Osman: Obtained her master's degree in Operational Research and Systems Analysis, The University of Aston In Birmingham, United Kingdom (1985), and Ph.D. in Computer Science (1996) at University of Salford, United Kingdom. Now is currently a Professor at School of Computing, Universiti Utara Malaysia. Her research expertise are teleworking, e-learning, e-government. 